\title{
Al-V (Aluminum-Vanadium)
}

\section{H. Okamoto}

The Al-V phase diagram in [Massalski2] was adopted from [1989Mur], who assessed this system mainly via the work of [1955Car] and [1959Bai]. Part of the [1989Mur] diagram is shown in Fig. 1 with dashed lines. [2000Ric] reinvestigated the $\mathrm{Al}-\mathrm{V}$ phase diagram in the composition range between 0 and 50 at.\% $\mathrm{V}$ using differential thermal analysis, $\mathrm{x}$-ray diffraction, and electron probe microanalysis. The result is shown with solid lines in Fig. 1. The difference between [1989Mur] and [2000Ric] is significant particularly with regard to the melting temperatures of $\mathrm{Al}_{3} \mathrm{~V}$ and $\mathrm{Al}_{8} \mathrm{~V}_{5}$. Experimental data are needed for the
(V) liquidus and solidus to complete the diagram of [2000Ric].

\section{References}

1955Car: O.N. Carlson, D.J. Kenney, and H.A. Wilhelm: Trans. ASM, 1955, vol. 47, pp. 520-36.

1959Bai: D.M. Bailey, O.N. Carlson, and J.F. Smith: Trans. ASM, 1959, vol. 51, pp. 1097-1102.

1989Mur: J.L. Murray: Bull. Alloy Phase Diagrams, 1989, vol. 10 (4), pp. 351-57.

2000Ric: K.W. Richter and H. Ipser: Z. Metallkd., 2000, vol. 91 (5), pp. 383-88.

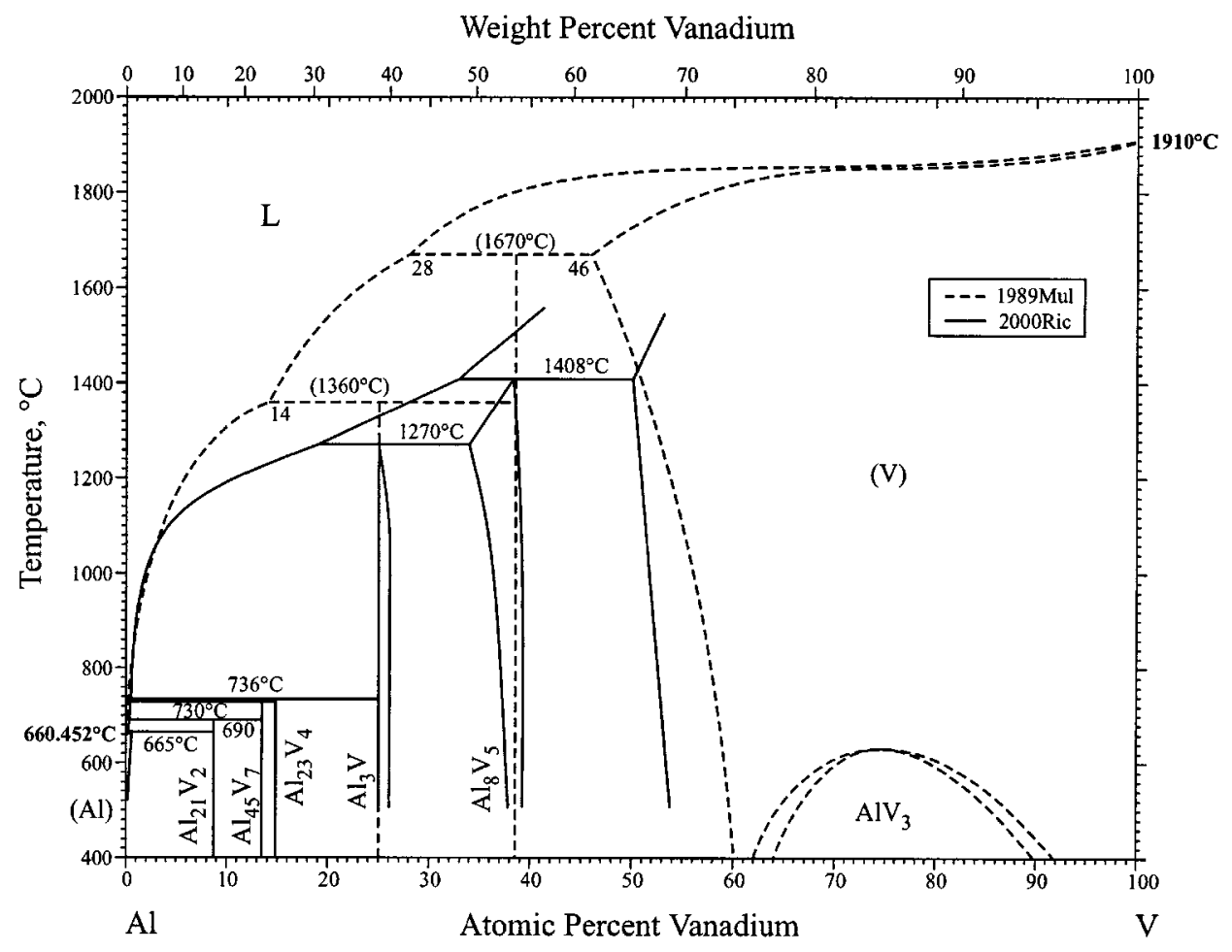

Fig. 1 Al-V phase diagram 